\title{
Pengaruh Pengembangan Karier Terhadap Produktivitas Tenaga Kerja (Studi Kasus Pada Departemen Produksi PT. Perusahaan Logam Bima Bandung Tahun 2019)
}

\author{
Hersusetiyati ${ }^{1}$, Agus Sopyan ${ }^{2}$ \\ ${ }^{1}$ Dosen Program Studi Administrasi Bisnis \\ ${ }^{2}$ Mahasiswa Program Studi Administrasi Bisnis \\ Universitas Sangga Buana YPKP Bandung \\ ${ }^{1}$ Hersusetiyati@gmail.com
}

\begin{abstract}
ABSTRAK
Tujuan penelitian ini adalah untuk mengetahui dan menganalisis bagaimana pengembangan karier mempengaruhi produktivitas yang terjadi pada tenaga kerja, serta besarnya pengaruh pengembangan karier terhadap produktivitas di Departemen Produksi PT. Perusahaan Logam Bima Bandung. Metode yang digunakan dalam penelitian adalah metode kuantitatif dengan jenis Asosiatif-kausal. Pengambilan sampel dilakukan dengan metode proportionate stratified random sampling, dengan jumlah responden sebanyak 110 orang. Teknik analisis data yang digunakan adalah analisis deskriptif dan analisis regresi linier sederhana. Hasil analisis regresi menunjukkan bahwa pengembangan karier berpengaruh positif terhadap produktivitas tenaga kerja pada Departemen Produksi PT. Perusahaan Logam Bima Bandung. Pengujian hipotesis membuktikan pengembangan karier berpengaruh terhadap produktivitas tenaga kerja pada Departemen Produksi PT. Perusahaan Logam Bima Bandung. Pengembangan karier pada Departemen Produksi PT. Perusahaan Logam Bima Bandung sudah masuk kedalam kategori cukup baik, namun ada beberapa item yang perlu diperbaiki seperti perbaikan progam perencanaan sumber daya manusia, perbaikan program pendidikan dan pelatihan untuk tenaga kerja serta perbaikan sistem jaminan sosial dan penghasilan.
\end{abstract}

Kata Kunci: Pengembangan Karier, Produktivitas Tenaga Kerja.

\section{ABSTRACT}

The purpose of this study was to determine and analyze how career development affects productivity that occurs in the workforce, and the magnitude of the influence of career development on productivity in the Production Department of PT. Perusahaan Logam Bima Bandung. This research uses quantitative methods with associative-causal type. Sampling was done by proportionate stratified random sampling method, with 110 respondents. The data analysis technique used is descriptive analysis and simple linear regression analysis. The results showed that career development had a positive effect on labor productivity at the Production Department of PT. Perusahaan Logam Bima Bandung. Hypothesis testing proves career development has an effect on labor productivity at the Production Department of PT. Perusahaan Logam Bima Bandung. The conclusion of this research is that career development at the Production Department of PT. Bima Metal Company Bandung has entered into a fairly good category, but there are some items that need to be improved, such as improving human resource planning programs, education and training programs for workers and social security systems and income.

Keywords: Career Development, Labor Productivity. 


\section{PENDAHULUAN}

Perusahaan pada berbagai sektor, baik itu yang menawarkan produk maupun jasa tentu akan saling berkompetisi untuk selalu unggul dalam mengambil hati masyarakat. Keunggulan tidak akan dapat terealisasikan tanpa pemanfaatan secara maksimal segala sumber daya yang ada di dalam suatu perusahaan. Peranan terpenting guna menggiatkan tercapainya tujuan perusaaan ialah sumber daya manusianya, sebab apalah artinya keunggulan teknologi tanpa didukung dengan sumber daya manusia yang berkualitas. Perusahaan di berbagai sektor pada umumnya mempunyai tujuan untuk meningkatkan produktivitas perusahaan. Produktivitas perusahaan pada dasarnya adalah perwujudan dari produktivitas tenaga kerja.

Perusahaan yang besar dikenal sebagai perusahaan yang berani menjamin kehidupan yang lebih baik untuk para tenaga kerjanya. Namun, itu bukan berarti kesuksesan dibebankan pada perusahaan semata. Semua tenaga kerja dalam suatu perusahaan juga merupakan aktor dalam keberhasilan perusahaan. Tidak peduli apa jabatannya, namun para tenaga kerja ini berhak mendapatkan balasan yang setimpal. Balasan bukan hanya soal gaji, tunjangan, dan bonus. Tapi juga berupa ilmu yang membuat kemampuan mereka berkembang. Karena perkembangan kemampuan juga akan membawa mereka pada perkembangan karier yang baik. Sehingga sudah menjadi tugas perusahaan untuk membuat beberapa program pengembangan karier.

Program pengembangan karier bisa berupa apa saja. Mulai dari soft skill seperti cara mengelola emosi, hingga hard skill misal kemampuan public speaking. Semua bentuk program pengembangan karier tersebut pasti memiliki tujuan yang disesuaikan dengan kondisi dan keadaan tenaga kerja. Jika perlu justru memberikan wadah bagi tenaga kerja untuk menyalurkan passion mereka. Adapun manfaat pengembangan karier bagi tenaga kerja seperti: Tenaga kerja lebih mengenal diri sendiri; Lebih aman karena jaminan kesejahteraan; Relasi semakin berkembang; Partisipasi tenaga kerja meningkat; Peningkatan motivasi bekerja. Artinya, perusahaan harus mampu membuat program pengembangan karier yang baik sesuai kebutuhan tenaga kerjanya.

PT. Perusahaan Logam Bima Bandung merupakan perusahaan yang berfokus dalam memproduksi peralatan dapur dan peralatan masak yang memiliki beberapa pabrik di tiga lokasi berbeda, yaitu Bandung (pusat), Cisangkan, dan Cimareme. Khusus di Bandung (pusat), selain sebagai tempat produksi juga terdapat showroom sehingga konsumen bisa datang langsung ke lokasi jika ingin membeli produk.

Dalam dua tahun terakhir (2017 dan 2018), produktivitas perusahaan mengalami penurunan dari $93,28 \%$ menjadi 91,4\% sehingga dilakukan penelitian dengan meneliti pengembangan karier sebagai variabel independen karena penulis melihat fenomena di perusahaan dimana pengembangan karier kurang diperhatikan.

\section{TINJAUAN PUSTAKA}

\section{Pengembangan Karier}

Menurut Dessler (2016:5), mengemukakan bahwa pengembangan karier merupakan serangkaian aktivitas sepanjang hidup (seperti workshop) yang berkontribusi pada eksplorasi, pemantapan, keberhasilan, dan pencapaian karier seseorang. Menurut Andrew J. Fubrin dalam Mangkunegara (2017:77) mengemukakan bahwa "Career development, from the standpoint of the organization, is the personnel activity which helps individuals plan their future career within the enterprise, in order help to the enterprise achieve and the employee achieve maximum self-development". Berdasarkan pendapat Andrew J. Dubrin 
di atas, pengembangan karier adalah aktivitas kepegawaian yang membantu pegawai-pegawai merencanakan karier masa depan mereka di perusahaan agar perusahaan dan pegawai yang bersangkutan dapat mengembangkan diri secara maksimum. Menurut Sedarmayanti (2017:183) pengembangan karier adalah proses mengidentifikasi potensi karier pegawai dan materi serta menerapkan cara-cara yang tepat untuk mengembangkan potensi tersebut.

Fokus yang mempengaruhi pengembangan karier menurut Dessler (2016:5) adalah sebagai berikut :

1. Perencanaan sumber daya manusia

2. Pelatihan dan pengembangan

3. Penilaian prestasi

4. Perekrutan dan penempatan

5. Kompensasi dan tunjangan

\section{Produktivitas Tenaga Kerja}

Menurut Sedarmayanti (2017:341), secara umum produktivitas merupakan perbandingan antara hasil yang dicapai dan keseluruhan daya atau faktor produksi yang dipergunakan. Sedangkan produktivitas pegawai merupakan perbandingan antara hasil yang dicapai dan peran serta pegawai per satuan waktu. Atau sejumlah barang dan jasa yang dapat dihasilkan seseorang atau sekelompok orang atau pegawai dalam jangka waktu tertentu. Menurut M. Sinungan dalam Sedarmayanti (2017:341) bahwa produktivitas adalah hubungan antara hasil nyata ataupun fisik (barang dan jasa) dan masukan yang sebenarnya.

Menurut Komarudin dalam Sedarmayanti (2017:341) bahwa produktivitas adalah kemampuan untuk menghasilkan barang atau jasa yang biasanya dihitung per jam, per bulan, per mesin, dan per faktor produksi lainnya. Menurut Sedarmayanti (2017:344) mengemukakan bahwa beberapa faktor yang mempengaruhi produktivitas pegawai, yaitu:

1. Pendidikan dan latihan

2. Gizi dan kesehatan

3. Penghasilan dan jaminan sosial

4. Kesempatan kerja

\section{Hipotesis Penelitian}

$\mathrm{H}_{0}$ : Tidak ada Pengaruh Pengembangan Karier Terhadap Produktivitas Tenaga Kerja di Departemen Produksi PT. Perusahaan Logam Bima Bandung.

$\mathrm{H}_{\mathrm{a}}$ : Ada Pengaruh Pengembangan Karier Terhadap Produktivitas Tenaga Kerja di Departemen Produksi PT. Perusahaan Logam Bima Bandung.

\section{Kerangka Pemikiran Penelitian}

\section{Pengembangan karier $(\mathrm{X})$ : \\ a. Perencanaan Sumber Daya Manusia \\ b. Pelatihan dan Pengembangan \\ c. Penilaian Prestasi \\ d. Perekrutan dan Penempatan \\ e. Kompensasi dan Tunjangan}

(Dessler, 2016:5)
Produktivitas Kerja (Y):

a. Pendidikan dan Latihan

b. Gizi dan Kesehatan

c. Penghasilan dan Jaminan Sosial

d. Kesempatan Kerja

(Sedarmayanti, 2017:344)

\section{Gambar 1 Kerangka Pemikiran Penelitian}

Sumber: olah data penulis (2019) 


\section{METODOLOGI}

Penelitian ini menggunakan metode kuantitatif. Menurut Sugiyono (2018:8) metode penelitian kuantitatif dapat diartikan sebagai metode penelitian yang berlandaskan pada filsafat positivisme, digunakan untuk meneliti pada populasi atau sampel tertentu, pengumpulan data menggunakan instrument penelitian, analisis data bersifat kuantitatif/statistik, dengan tujuan untuk menguji hipotesis yang telah ditetapkan. Jenis penelitian ini termasuk penelitian assosiatif dengan hubungan kausal.

Penelitian assosiatif kausal menurut Sugiyono (2018:37) adalah penelitian yang dimaksudkan untuk mengungkapkan permasalahan yang bersifat hubungan sebab akibat antara dua variabel atau lebih. Faktual dan akurat mengenai faktafakta berisikan dokumen-dokumen berhubungan dengan hal-hal berikut, yaitu meneliti bahwa pengaruh antara pengembangan karier sebagai variabel "X" yang berfungsi mempengaruhi produktivitas tenaga kerja sebagai variabel "Y" yang berfungsi sebagai yang dipengaruhi.

Lokasi penelitian dilaksanakan di PT. Perusahaan Logam Bima Bandung yang berlokasi di Jalan Arjuna No. 56-58, Bandung - Jawa Barat, sedangkan objek pada penelitian ini adalah Pengembangan Karier dan Produktivitas Tenaga Kerja di PT. Perusahaan Logam Bima Bandung.

Populasi pada penelitian ini adalah tenaga kerja PT. Perusahaan Logam Bima Bandung yang berjumlah 160 orang. Teknik penarikan sampel dalam penelitian ini menggunakan tabel Isaac dan Michael sehingga sampel yang diambil adalah 110 orang (significance level 5\%) serta menggunakan Proportionate Stratified Random Sampling yaitu pengambilan sampel dimana populasi berstrata secara proporsional.

Metode analisis yang digunakan yaitu analisis deskriptif, uji validitas dan reliabilitas, uji normalitas, analisis regresi linier sederhana, dan uji hipotesis. Untuk memudahkan proses pengolahan data, analisis menggunakan bantuan software SPSS versi 25.0.

\section{HASIL DAN PEMBAHASAN}

\section{Uji Validitas dan Reliabilitas}

\section{Hasil Uji Validitas}

Pada tabel 1, $\mathrm{n}=30$, dalam kolom $\mathrm{r}$ hitung diketahui nilai korelasi masingmasing butir pertanyaan yang diuji. Jika nilai $r$ hitung suatu butir di atas $r$ tabel dengan $\mathrm{df}=30-2=28$ dan $\alpha=5 \%$ diperoleh nilai $r$ tabel sebesar 0,361 maka dapat disimpulkan bahwa butir tersebut adalah valid. Sebaliknya jika nilai $r$ hitung suatu butir di bawah $r$ tabel $(0,361)$ maka disimpulkan bahwa butir tersebut tidak valid (dinyatakan gugur). Tabel 1 menunjukkan bahwa seluruh butir pertanyaan memiliki nilai $r$ hitung di atas r tabel $(0,361)$ sehingga dapat disimpulkan bahwa butir tersebut secara keseluruhan adalah valid.

Tabel 1

Hasil Uji Validitas Instrumen

\begin{tabular}{ccccc}
\hline Variabel & $\begin{array}{c}\text { No. } \\
\text { Item }\end{array}$ & $\begin{array}{c}\text { r } \\
\text { hitung }\end{array}$ & $\begin{array}{c}\text { r } \\
\text { tabel }\end{array}$ & Ket. \\
\hline & X.1 & 0,611 & 0,361 & Valid \\
& X.2 & 0,661 & 0,361 & Valid \\
& X.3 & 0,764 & 0,361 & Valid \\
& X.4 & 0,826 & 0,361 & Valid \\
& X.5 & 0,834 & 0,361 & Valid \\
Pengemb & X.6 & 0,858 & 0,361 & Valid \\
angan & X.7 & 0,855 & 0,361 & Valid \\
Karier & X.8 & 0,774 & 0,361 & Valid \\
(X) & X.9 & 0,713 & 0,361 & Valid \\
& X.10 & 0,847 & 0,361 & Valid \\
& X.11 & 0,862 & 0,361 & Valid \\
& X.12 & 0,791 & 0,361 & Valid \\
& X.13 & 0,673 & 0,361 & Valid \\
& X.14 & 0,776 & 0,361 & Valid \\
& X.15 & 0,586 & 0,361 & Valid \\
& Y.1 & 0,675 & 0,361 & Valid \\
& Y.2 & 0,710 & 0,361 & Valid \\
Produkti & Y.3 & 0,550 & 0,361 & Valid \\
Vitas & Y.4 & 0,806 & 0,361 & Valid \\
Kenaga & Y.6 & 0,681 & 0,361 & Valid \\
& Y.7 & 0,615 & 0,361 & Valid \\
& Y.8 & 0,663 & 0,361 & Valid \\
& Y.9 & 0,769 & 0,361 & Valid \\
\hline Sumber : Data & Primer & diolah $(2019)$ & Valid \\
& Y.10 & 0,815 & 0,361 & Valid \\
\hline
\end{tabular}

Sumber : Data Primer, diolah (2019) 


\section{Hasil Uji Reliabilitas}

Berdasarkan hasil pengujian terhadap seluruh butir pertanyaan yang ada sebagaimana pada tabel 2, diketahui bahwa nilai Spearman Brown secara keseluruhan berada di antara 0,8 - 1,00 sehingga dapat disimpulkan bahwa instrumen kuesioner tersebut menunjukkan reliabilitas sangat kuat.

Tabel 2

Hasil Uji Reliabilitas Instrumen

\begin{tabular}{ccl}
\hline Variabel & $\begin{array}{c}\text { Spearman } \\
\text { Brown }(\mathrm{R})\end{array}$ & Keterangan \\
\hline $\begin{array}{c}\text { Pengembangan } \\
\text { Karier (X) }\end{array}$ & 0,947 & $\begin{array}{l}\text { Reliabilitas } \\
\text { sangat kuat }\end{array}$ \\
$\begin{array}{c}\text { Produktivitas } \\
\text { tenaga kerja (Y) }\end{array}$ & 0,866 & $\begin{array}{l}\text { Reliabilitas } \\
\text { sangat kuat }\end{array}$ \\
\hline
\end{tabular}

Sumber: Data Primer, diolah

\section{Uji Normalitas}

\section{Probability Plot (P-Plot)}

Gambar 2 menunjukkan bahwa P-Plot memiliki pola distribusi normal karena pencaran data berada tepat di sekitar garis diagonal dan mengikuti garis diagonal tersebut.

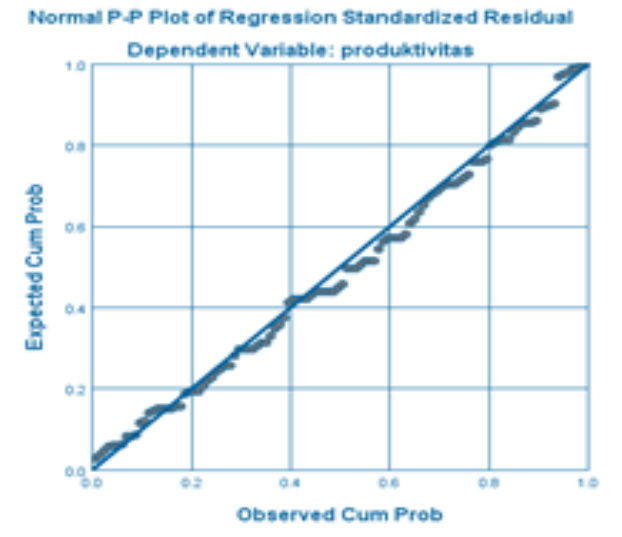

Gambar 2 Hasil Uji P-Plot

Sumber : SPSS, 25.0, Tahun 2019

\section{Kolmogorov-Smirnov}

Gambar 3 digunakan uji Kolmogorov-Smirnov, tampak nilai Sig. $(0,200)>0,05$ artinya data berdistribusi normal. Dengan demikian dapat dikatakan bahwa penelitian ini telah memenuhi asumsi normalitas.
One-Sample Kolmogorov-Smirnov Test

\begin{tabular}{|c|c|c|}
\hline & & $\begin{array}{l}\text { Unstandardized } \\
\text { Residual }\end{array}$ \\
\hline \multicolumn{2}{|l|}{$\mathbf{N}$} & 110 \\
\hline \multirow{2}{*}{$\begin{array}{l}\text { Normal } \\
\text { Parametersa,b }\end{array}$} & Mean & .0000000 \\
\hline & $\begin{array}{l}\text { Std. } \\
\text { Deviation }\end{array}$ & 2.79385103 \\
\hline \multirow{3}{*}{$\begin{array}{l}\text { Most Extreme } \\
\text { Differences }\end{array}$} & Absolute & .058 \\
\hline & Positive & .058 \\
\hline & Negative & -.033 \\
\hline \multicolumn{2}{|l|}{ Test Statistic } & .058 \\
\hline \multicolumn{2}{|c|}{ Asymp, Sig (2-tailed) } & 200 ad \\
\hline \multicolumn{3}{|c|}{ a. Test distribution is Normal. } \\
\hline \multicolumn{3}{|c|}{ b. Calculated from data. } \\
\hline \multicolumn{3}{|c|}{ c. Lilliefors Significance Correction. } \\
\hline \multicolumn{3}{|c|}{ d. This is a lower bound of the true significance } \\
\hline
\end{tabular}

Gambar 3 Hasil Uji Kolmogorov-Smirnov

Sumber : SPSS, 25.0, Tahun 2019

\section{Analisis Agresi Linier Sederhana}

Berdasarkan tabel 3 maka diperoleh persamaan :

$$
\begin{array}{ll}
\hat{\mathrm{Y}} & =\mathrm{a}+\mathrm{bX} \\
\hat{\mathrm{Y}} & =11,358+0,422 \mathrm{X}
\end{array}
$$

Persamaan di atas menunjukkan besar koefisien regresi variabel pengembangan karier adalah positif yaitu 0,422 yang menunjukkan adanya pengaruh positif pengembangan karier terhadap produktivitas tenaga kerja. Jika pengembangan karier menurun satu satuan maka akan menurunkan produktivitas tenaga kerja sebesar 0,422 dan sebaliknya. Jika pengembangan karier bernilai nol maka produktivitas tenaga kerja bernilai 11,358.

\section{Tabel 3}

Hasil Analisis Regresi Linier Sederhana

\begin{tabular}{|c|c|c|c|c|c|c|}
\hline \multirow{2}{*}{\multicolumn{2}{|c|}{ Model }} & \multicolumn{2}{|c|}{$\begin{array}{l}\text { Unstandardized } \\
\text { Coefficients }\end{array}$} & \multirow{2}{*}{ 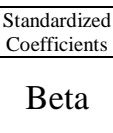 } & \multirow[b]{2}{*}{$\mathrm{T}$} & \multirow[b]{2}{*}{ Sig. } \\
\hline & & B & $\begin{array}{l}\text { Std. } \\
\text { Error }\end{array}$ & & & \\
\hline \multirow[t]{2}{*}{1} & $\begin{array}{c}\text { (Consta } \\
\text { nt) }\end{array}$ & 1.358 & 2.947 & & 3.854 & .000 \\
\hline & $\begin{array}{c}\text { Pengem } \\
\text { bangan } \\
\text { Karier } \\
\text { (X) }\end{array}$ & .422 & .065 & .531 & 6.508 & .000 \\
\hline
\end{tabular}

Coefficients $^{\mathrm{a}}$

a. Dependent Variable: Produktivitas (Y) Sumber : SPSS, 25.0, Tahun 2019

\section{Koefisien Determinasi}

Berdasarkan tabel 4, diketahui bahwa besarnya koefisien korelasi antara 
pengembangan karier dengan produktivitas tenaga kerja adalah 0,531 yang menunjukkan hubungan cukup. Sehingga diperoleh nilai Koefisien determinasi $(\mathrm{KD})$ sebagai berikut :

$\mathrm{KD}=\mathrm{r}^{2} \times 100 \%$

$$
\begin{aligned}
& =(0,531)^{2} \times 100 \% \\
& =0,282 \times 100 \% \\
& =28,2 \%
\end{aligned}
$$

Dengan demikian, koefisien determinasinya adalah $28,2 \%$ yang berarti produktivitas tenaga kerja sebesar 28,2 \% ditentukan oleh pengembangan karier sedangkan sisanya $71,8 \%$ dipengaruhi oleh faktor lain yang tidak diteliti. Sehingga pengaruh pengembangan karier terhadap produktivitas tenaga kerja sebesar $28,2 \%$.

\section{Tabel 4}

Koefisien Korelasi dan Determinasi Model Summary ${ }^{\mathrm{b}}$

\begin{tabular}{ccccc}
\hline Model & $\mathrm{R}$ & $\begin{array}{c}\mathrm{R} \\
\text { Square }\end{array}$ & $\begin{array}{c}\text { Adjusted } \\
\mathrm{R} \text { Square }\end{array}$ & $\begin{array}{c}\text { Std. Error of the } \\
\text { Estimate }\end{array}$ \\
\hline 1 & $.531^{\mathrm{a}}$ & .282 & .275 & 3.75599 \\
\hline
\end{tabular}

a. Predictors: (Constant), Pengembangan Karier (X)

b. Dependent Variable: Produktivitas (Y)

Sumber : SPSS, 25.0, Tahun 2019

\section{Pengujian Hipotesis}

Dasar dari pengambilan keputusan adalah :

a. Jika $t_{\text {hitung }}>t_{\text {tabel }}$ maka $\mathrm{H}_{0}$ ditolak atau - $\mathrm{t}_{\text {hitung }}$ $<-t_{\text {tabel }}$ maka H0 ditolak.

b. Jika $\mathrm{t}_{\text {hitung }}<\mathrm{t}_{\text {tabel }}$ maka $\mathrm{H}_{0}$ diterima atau $t_{\text {hitung }}>-t_{\text {tabel }}$ maka $\mathrm{H}_{0}$ diterima.

Atau :

a. Jika $p$ value $<0,05$ maka $\mathrm{H}_{0}$ ditolak.

b. Jika $p$ value $>0,05$ maka $\mathrm{H}_{0}$ diterima.

Pada tabel 3 tampak nilai thitung sebesar 6,508. Sedangkan harga kritis nilai tabel dengan derajat bebas $\mathrm{n}-2=110$ $-2=108$ pada $\alpha(0,05)$ sebesar $\pm 1,984$. Dengan demikian thitung $(6,508)>t_{\text {tabel }}$ $(1,984)$ atau $p$-value $(0,000)<0,05$, sehingga $\mathrm{H}_{0}$ ditolak. Hal ini menunjukkan bahwa terdapat pengaruh pengembangan karier dengan produktivitas tenaga kerja (lihat gambar 4).

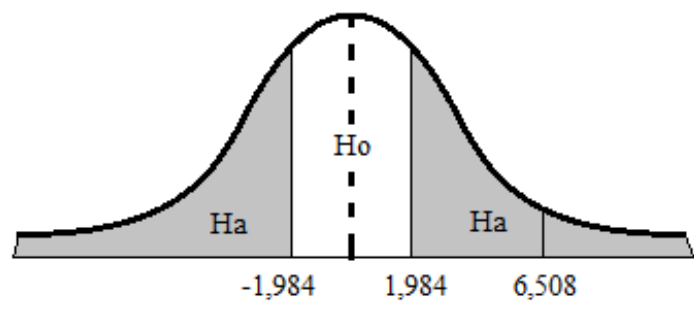

Gambar 4 Hasil Pengujian Hipotesis

Sumber : Olah data penelitian, 2019

\section{Analisis Deskriptif}

Untuk variabel pengembangan karier diketahui bahwa penilaian responden berada dalam kategori setuju dengan skor aktual 6109. Persentase yang diperoleh adalah $6109 /(5 \times 15 \times 110) \times 100 \%=$ $6109 / 8250 \times 100 \%=74,0 \%$.

Tabel 5

Rekapitulasi Skor Variabel Pengembangan Karier

\begin{tabular}{clcc}
\hline No. & Pengembangan Karier & & Skor \\
\hline 1 & $\begin{array}{l}\text { Dimensi perencanaan sumber } \\
\text { daya manusia }\end{array}$ & 935 \\
2 & $\begin{array}{l}\text { Dimensi pelatihan } \\
\text { pengembangan }\end{array}$ & dan & 1257 \\
3 & $\begin{array}{l}\text { Dimensi penilaian prestasi } \\
\text { Dimensi perekrutan dan }\end{array}$ & 1366 \\
4 & $\begin{array}{l}\text { penempatan } \\
5\end{array}$ & $\begin{array}{l}\text { Dimensi kompensasi } \\
\text { tunjangan dan }\end{array}$ & 1318 \\
\hline \multicolumn{2}{c}{ Total } & & $\mathbf{6 1 0 9}$ \\
\hline
\end{tabular}

Sumber : Data Penelitian 2019

Untuk variabel produktivitas tenaga kerja diketahui bahwa penilaian responden berada dalam kategori setuju dengan skor aktual 4206. Persentase yang diperoleh adalah 4206/ $(5 \times 10 \times 110) \times 100 \%=$ $4206 / 5500 \times 100 \%=76,4 \%$.

Tabel 6

Rekapitulasi Skor Variabel Produktivitas Tenaga Kerja

\begin{tabular}{clc}
\hline No. & Produktivitas Tenaga Kerja & Skor \\
\hline 1 & Dimensi pendidikan dan latihan & 663 \\
2 & Dimensi gizi dan kesehatan & 1309 \\
3 & Dimensi penghasilan dan jaminan & 897 \\
& sosial & 1337 \\
4 & Dimensi kesempatan kerja & $\mathbf{4 2 0 6}$ \\
\hline
\end{tabular}

Sumber : Data Penelitian 2019 


\section{Pengaruh Pengembangan Karier Terhadap Produktivitas Tenaga Kerja}

Berdasarkan hasil analisis data yang telah dilakukan menunjukkan bahwa terdapat pengaruh yang positif dan signifikan antara pengembangan karier terhadap produktivitas tenaga kerja di Departemen Produksi PT. Perusahaan Logam Bima Bandung. Pernyataan ini dibuktikan dengan hasil perhitungan pada hipotesis dengan menggunakan uji t yang menghasilkan nilai thitung sebesar 6,508. Sedangkan harga kritis nilai $t_{\text {tabel }}$ dengan derajat bebas $n-2=110-2=108$ pada $\alpha$ $(0,05)$ sebesar $\pm 1,984$. Dengan demikian $t_{\text {hitung }}(6,508)>t_{\text {tabel }}(1,984)$, sehingga $\mathrm{H}_{0}$ ditolak. Hal ini menunjukkan bahwa terdapat pengaruh pengembangan karier dengan produktivitas tenaga kerja.

Dari hasil perhitungan, diketahui besarnya koefisien korelasi (r) adalah 0,531 yang menunjukkan hubungan antara pengembangan karier dengan produktivitas tenaga kerja ialah cukup ada keterkaitannya. Dari hasil yang diperoleh koefisien determinan $\left(\mathrm{r}^{2}\right)$ sebesar 0,282. Hasil tersebut menunjukkan bahwa terdapat pengaruh pengembangan karier terhadap produktivitas tenaga kerja di Departemen Produksi PT. Perusahaan Logam Bima Bandung dengan persentase pengaruhnya sebesar $28,2 \%$ dan $71,8 \%$ dipengaruhi oleh variabel lain yang tidak diteliti dalam penelitian ini. Hasil penelitian ini sesuai dengan pendapat yang dikemukakan oleh Mali dalam Yuniarsih dan Suwatno (2016:160), bahwa produktivitas kerja merupakan sinergi dari semua faktor yang terbentuk pada empat level, yaitu : a) Pada level keempat (tertinggi), yang berpengaruh terhadap produktivitas secara langsung adalah efektivitas dan efisiensi (penggunaan sumber-sumber); b) Pada level ketiga, terdiri atas keterampilan, motivasi, metoda, dan biaya; c) Pada level kedua, terdiri atas kepemimpinan, pengalaman suasana, insentif, jadwal kerja, struktur organisasi, teknologi dan material; d) Pada level pertama, terdiri dari kecakapan, gaya, latihan, pengetahuan, kondisi fisik, rekan, bentuk tugas, tujuan, kebijakan, standar, perlengkapan dan kualitas.

Beberapa penelitian terdahulu yang penulis analisis seluruhnya menunjukkan hasil hipotesis yang sama, bahwa thitung $>$ $t_{\text {tabel }}$ sehingga Ho ditolak. Hal tersebut menunjukkan bahwa terdapat hubungan antara variabel X terhadap Y. Meskipun terdapat perbedaan penelitian terdahulu dengan penelitian ini yaitu dari analisis yang digunakan oleh Nasruddin Setiyawan (2017) dan F. Andi Budi P. (2016) yang menggunakan regresi linier berganda, lalu penelitian oleh Rini Suhendra (2013) yang menggunakan teknik Total Sampling, semua hasil penelitian tetap menunjukkan adanya pengaruh X terhadap Y.

\section{KESIMPULAN}

Berdasarkan hasil penelitian mengenai pengaruh Pengembangan Karier Terhadap Produktivitas Tenaga Kerja pada Departemen Produksi PT. Perusahaan Logam Bima Bandung, peneliti dapat menyimpulkan sebagai berikut :

1. Berdasarkan rekapitulasi rata-rata skor tanggapan responden untuk variabel pengembangan karier diketahui penilaian responden berada dalam kategori setuju dengan skor aktual 6109 dan persentase 74,0\%. Dari hasil analisis deskriptif tersebut, dapat diketahui bahwa secara keseluruhan Pengembangan Karier di Departemen Produksi PT. Perusahaan Logam Bima Bandung sudah berjalan dengan cukup baik walaupun masih ada kekurangan yang harus dioptimalkan lagi.

2. Berdasarkan pada nilai rata-rata skor tanggapan responden yang telah dilakukan pengolahannya bahwa nilai tersebut menunjukan hasil di kategori setuju yaitu sebesar $76,4 \%$ dengan skor aktual 4206. Dari hasil analisis deskriptif tersebut, dapat diketahui bahwa secara keseluruhan 
Produktivitas Tenaga Kerja di Departemen Produksi PT. Perusahaan Logam Bima Bandung sudah cukup baik meskipun masih kurang optimal.

3. Faktor pengembangan karier secara statistik berpengaruh positif dan signifikan terhadap upaya meningkatkan produktivitas tenaga kerja pada Departemen Produksi PT. Perusahaan Logam Bima Bandung.

\section{DAFTAR PUSTAKA}

Dessler, Gary. 2016. Manajemen Sumber Daya Manusia Edisi Kesepuluh Jilid 2. Jakarta: PT Indeks.

F. Andi Budi P. 2016. "Pengaruh Pengembangan Karier Dan Komunikasi Terhadap Komitmen Karyawan Yang Berdampak Pada Produktivitas Kerja (studi kasus karyawan di CV. Tirta Minerva Semarang)". Journal of Management, Vol. 2, 2016.

Mangkunegara, Anwar Prabu. 2017. Manajemen Sumber Daya Manusia Perusahaan. Bandung: PT. Remaja Rosdakarya.

Sedarmayanti. 2017. Perencanaan Dan Pengembangan SDM Untuk Meningkatkan Kompetensi, Kinerja, Dan Produktivitas Kerja. Bandung: PT. Refika Aditama.

Setiyawan, Nasrudin. 2017. "Pengaruh Performance, Orientasi dan Pengembangan Karier Terhadap Produktivitas Kerja Pada PT. Gudang Garam Tbk. Cabang Medan". Jurnal Ilmiah "DUNIA ILMU”, Vol.3, 2017.

Suhendra, Rini. 2013. "Pengaruh Perencanaan dan Pengembangan Karier Terhadap Produktivitas Kerja Pegawai di PT. Bank Sumut Kantor Cabang Pembantu USU Medan".

Sugiyono. 2018. Metode Penelitian Kuantitatif, Kualitatif Dan R\&D. Bandung: CV. Alfabeta.
Yuniarsih, T. dan Suwatno. 2016. Manajemen Sumber Daya Manusia. Bandung: CV. Alfabeta. 